\title{
Ranibizumab in Diabetic Macular Edema; Level 1 and Level 2 Studies Findings
}

\author{
Arief Kartasasmita', Elvis Elvioza', Habibah S Muhiddin ${ }^{3}$ \\ ${ }^{1}$ Department of Ophthalmology Faculty of Medicine Universitas Padjajaran, Indonesia \\ ${ }^{2}$ Department of Ophthalmology Faculty of Medicine Universitas Indonesia, Indonesia \\ ${ }^{3}$ Department of Ophthalmology Faculty of Medicine Universitas Hasanudin, Indonesia
}

\begin{abstract}
INTRODUCTION. Ranibizumab is an anti-VEGF antibody widely used in DME treatment.

MATERIALS AND METHODS. We conducted a literature search using the keywords "diabetes", "diabetic retinopathy", "diabetic macular edema", "pathophysiology", "VEGF", "treatment", "anti-VEGF", "ranibizumab", "lucentis" with limitation of English language. The articles published between 2006-2016 years and we reviewed level I and level II studies.

RESULTS. Review from several level I and level II intravitreal ranibizumab injection studies suggests that ranibizumab is an anti-VEGF that effectively used in DME treatment. Comparison with other anti-VEGF also suggest that ranibizumab is effective for DME patients for over 2 years treatment.

CONCLUSIONS. Ranibizumab monotherapy and/or combination with laser is safe and effective for DME patients for over 2 years treatment.
\end{abstract}

KEY WORDS: diabetic macular edema, anti VEGF, ranibizumab

Ophthalmol J 2018; Vol. 3, No. 1, 14-20

\section{INTRODUCTION}

Diabetes is considered as chronic disease and diagnosed by observing the increase of blood glucose level.1 High blood glucose can lead to different organ damage including the eyes. $[1,2]$

Many aged 20-74 years diabetes develop some form of eye disease (Diabetic Retinopathy), with potential loss of vision [1-4].

Based on 2012 study, 35\% people with diabetes had some form of Diabetic Retinopathy and 7\% had Proliferative Diabetic Retinopathy, 7\% had Diabetic Macular Edema, and 10\% were affected by vision-threatening stages [5].

Diabetic Macular Edema (DME) is a common complication of diabetic retinopathy which is characterized by a swelling of the macular area due to leakage of proteins through vascular walls following the development of intracellular as well as extra- cellular hypertonic environments after an ischemic event $[6,7]$.

Vascular Endothelial Growth Factor (VEGF) is a major mediator of blood retinal barrier (BRB) breakdown and the development of macular edema.6 VEGF is a disulfide-bound homodimer glycoprotein. It is one of the most important regulators of vasculogenesis and angiogenesis. An inflammation-induced breakdown of the BRB is mediated by VEGF via binding to leukocytes and inducing their recruitment to the site of the inflammation. There are 5 types of VEGF which are VEGF-A, VEGF-B, VEGF-C, VEGF-D and VEGF-E. The VEGF that is involved in the development of macular edema in the eyes is mainly VEGF-A [7].

Therefore, currently, anti-VEGF treatment is one of the promising treatment of visual loss in DME patients $[6,8]$. 


\section{MATERIALS AND METHODS}

We conducted a literature search on PubMed ${ }^{\circledR}$, Google Scholar ${ }^{\mathrm{TM}}$, and Cochrane ${ }^{\circledR}$ databases using the keywords "diabetes", "diabetic retinopathy", "diabetic macular edema", "pathophysiology", "VEGF", "treatment", "anti-VEGF", "ranibizumab", "lucentis" with limitation of English language. The articles published between 2006-2016 years and we reviewed level I and level II studies.

Definition of level I studies are "high quality randomized trial or prospective study; testing of previously developed diagnostic criteria on consecutive patients; sensible costs and alternatives; values obtained from many studies with multiway sensitivity analyses; systematic review of Level I (RCT) and Level I studies" [9].

Level II studies are "less quality RCT; prospective comparative study; retrospective study; untreated controls from an RCT; less quality prospective study; development of diagnostic criteria on consecutive patients; sensible costs and alternatives; values obtained from limited studies; with multiway sensitivity analyses; systematic review of Level II studies or Level I studies with inconsistent results" [9].

\section{RESULTS}

Two anti-VEGF is approved for the DME treatment, ranibizumab (Lucentis; Genentech Inc., San Francisco, Calif., USA) and aflibercept (EYLEA; Regeneron, Tarrytown, N.Y., USA). Bevacizumab currently is not approved for diabetic macular edema but widely used as "off label".

Ranibizumab is a humanized monoclonal antibody that binds all biologically active isoforms and active proteolytic fragments of VEGF-A, therefore preventing VEGF-A to bind with its receptor. [10]

A pilot study of ranibizumab injection in $10 \mathrm{pa}-$ tients showed that ranibizumab is well tolerated, has potential to maintain or improve BCVA and reduce retinal thickness in patients with center-involved clinically significant DME [11].

Several level I studies such as Diabetic Retinopathy Clinical Network (DRCR.net), RESTORE Study, RISE and RIDE support the use of ranibizumab for DME patients. These studies reported that ranibizumab monotherapy or combination with laser give a better visual acuity outcomes at 1 to 2 years compared with laser or triamcinolone [12-15]. When comparing with other anti-VEGF (bevacizumab and aflibercept), one study (Protocol $\mathrm{T})$ showed that in year 1 among eyes with worse baseline VA, aflibercept showed superiority over ranibizumab and bevacizumab but at year 2, the superiority over ranibizumab was no longer identified (Table 1) $[16,17]$.

In The Diabetic Retinopathy Clinical Research Network (DRCR.net) evaluation of intravitreal $0.5 \mathrm{mg}$ ranibizumab or $4 \mathrm{mg}$ triamcinolone combined with focal/grid laser compared with focal/grid laser monotherapy for treatment of diabetic macular edema were studied.

A total 854 study eyes were randomized of combination sham injection and prompt laser $(\mathrm{n}=293)$, $0.5 \mathrm{mg}$ ranibizumab and prompt laser $(\mathrm{n}=187)$, $0.5 \mathrm{mg}$ ranibizumab and deferred laser $(\mathrm{n}=188)$, or $4 \mathrm{mg}$ triamcinolone and prompt laser $(\mathrm{n}=186)$. Prompt laser was given 3-10 days after injection while deferred laser was given $\geq 24$ weeks, intravitreal study drug or sham injection retreatments every 4 weeks based on criteria in the protocol [12].

The 1-year mean change in the visual acuity letter score from baseline was significantly greater in the combination of ranibizumab and prompt laser group and ranibizumab and deferred laser group (both +9 letters and $p<0.05$ ) but not in the combination of triamcinolone and prompt laser group ( +4 letters, $\mathrm{p}=0.31)$ compared with prompt laser monotherapy group ( +3 letters). Conclusion of the 2 -year expanded results are similar with to 1 -year results that combination of ranibizumab with prompt or deferred laser is more effective compared with prompt laser monotherapy $[12,13]$.

The study extended to 5-year and from 3-year follow up, the objective is to evaluate prompt versus deferred (for $\geq 24$ weeks) focal/grid laser treatment in eyes treated with intravitreal $0.5 \mathrm{mg}$ ranibizumab. Five-year result suggest that focal/grid laser treatment at the initiation of ranibizumab is no better than deferred laser $[18,19]$.

Another level I, RESTORE Study, a multicenter, randomized, double-masked, laser-controlled phase III study. Three hundred forty five DME patients randomized into 3 groups, $0.5 \mathrm{mg}$ ranibizumab + sham laser $(\mathrm{n}=116), 0.5 \mathrm{mg}$ ranibizum$a b+$ active laser $(n=118)$, or laser + sham injection $(\mathrm{n}=111)$. Ranibizumab/sham injection was given 3 months then pro re nata (PRN); laser/sham laser was given at baseline then PRN [14].

In the 12 month report, ranibizumab monotherapy and combination with laser were superior to laser alone in improving mean change in BCVA from baseline to month 1 through month $12(+6.1$ and +5.9 vs. +0.8 ; both $\mathrm{p}<0.0001)$. The mean cen- 


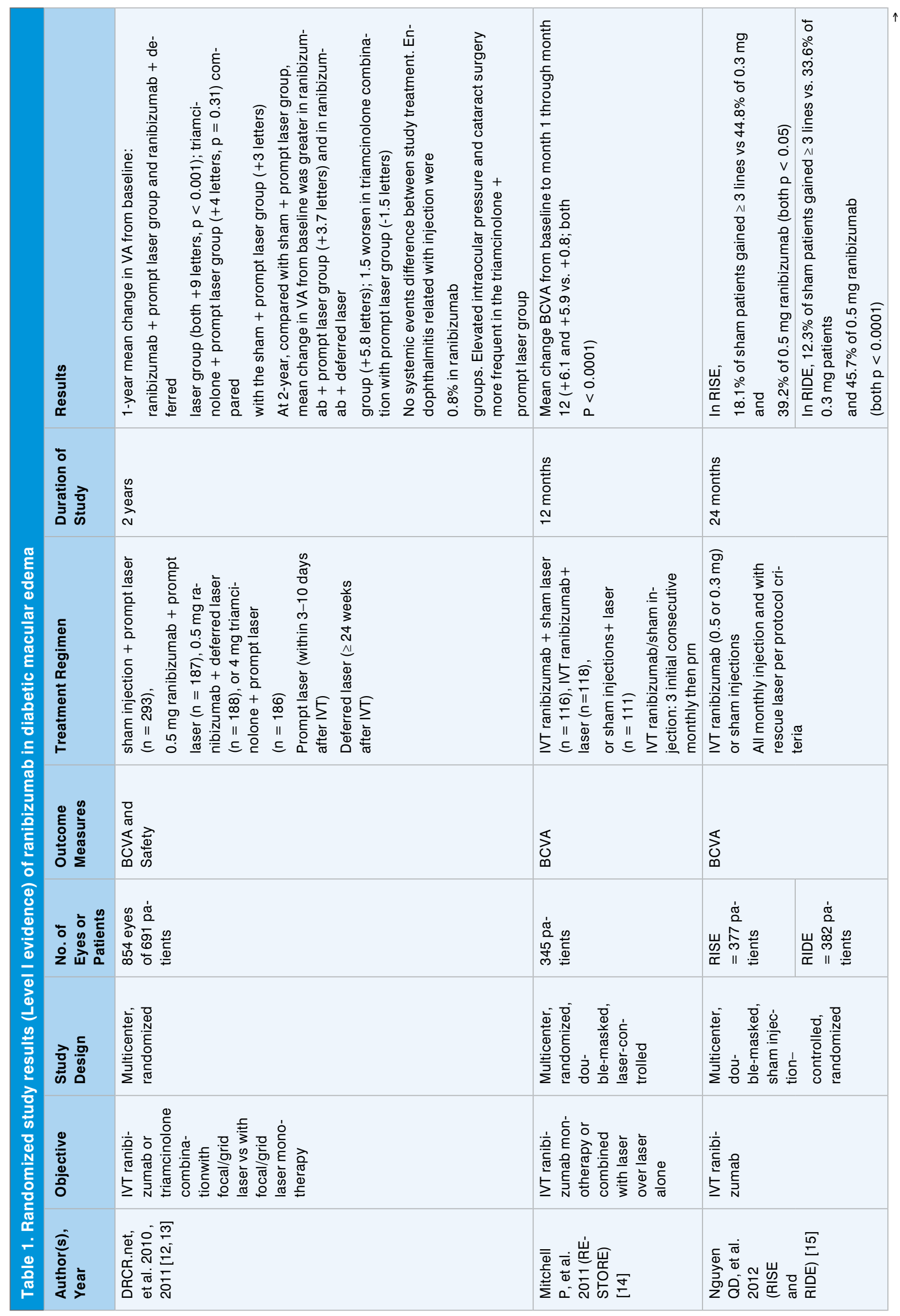




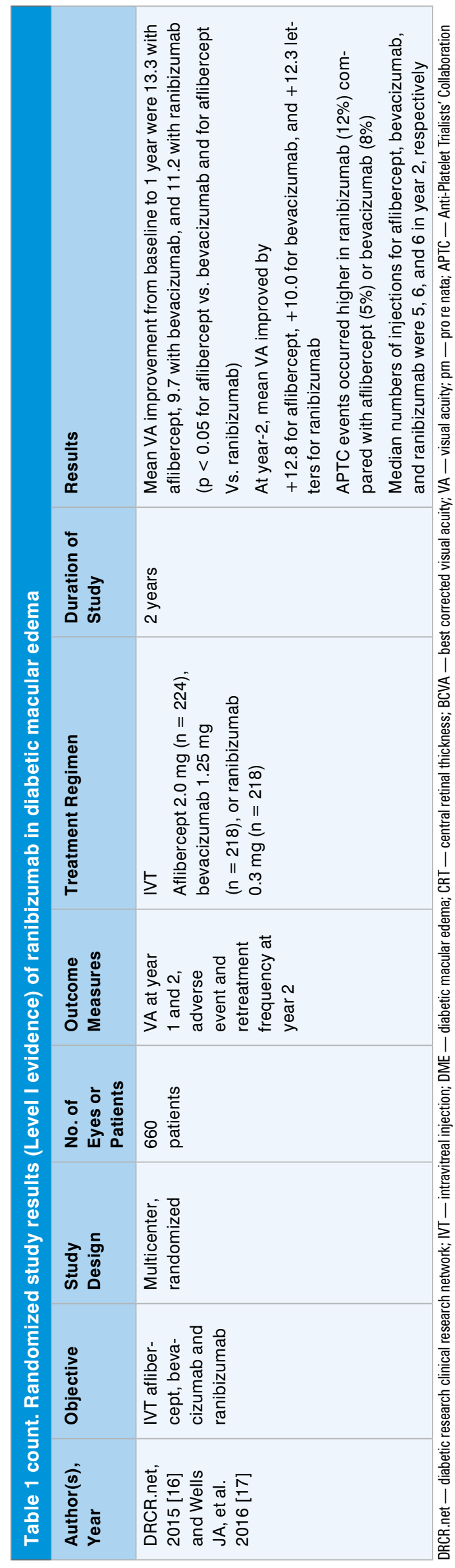

tral retinal thickness was significantly reduced from baseline with ranibizumab monotherapy $(-118.7 \mu \mathrm{m})$ and ranibizumab + laser combination $(-128.3 \mu \mathrm{m})$ versus laser monotherapy $(-61.3 \mu \mathrm{m}$; both $\mathrm{p}<0.001)$ [14].

All patients eligible to receive $0.5 \mathrm{mg}$ ranibizumab PRN from month 12 in RESTORE study included in extension study. Overall, 208 patients completed the extension study. Individualized ranibizumab treatment during the extension study could maintain the BCVA and central retinal thickness (CRT) observed at month 12 over the 2-year extension study $(+8.0$ letters, $-142.1 \mu \mathrm{m}$ [prior ranibizumab] and +6.7 letters, $-145.9 \mu \mathrm{m}$ [prior ranibizumab + laser] from baseline at month 36). Mean injection of 6.8 injections in prior ranibizumab group and 6.0 injections in prior ranibizumab + laser group. No new safety concern in ranibizumab group were identified [20,21].

Two parallel, methodologically identical, phase III, multicenter, double-masked, sham injection-controlled, randomized studies, RISE and RIDE. Ranibizumab was given monthly and in the third year, eligible patients sham patients cross-over to $0.5 \mathrm{mg}$ ranibizumab while still masked [15].

In RISE, 377 patients were randomized (sham $\mathrm{n}=127,0.3 \mathrm{mg}$ ranibizumab $\mathrm{n}=125,0.5 \mathrm{mg}$ ranibizumab $\mathrm{n}=125) .17,18$ At 24 months, $18.1 \%$ of sham patients gained $\geq 3$ lines versus $44.8 \%$ of $0.3 \mathrm{mg}$ and $39.2 \%$ of $0.5 \mathrm{mg}$ ranibizumab patients ( both $\mathrm{p}<0.05$ ) [15].

Visual acuity (VA) outcomes in ranibizumab group were consistent from month 24 through through month 36. Proportions of patients who gained $\geq 3$ lines from baseline at month 36 in the sham $/ 0.5 \mathrm{mg}, 0.3 \mathrm{mg}$, and $0.5 \mathrm{mg}$ ranibizumab groups were $22.0 \%, 51.2 \%$, and $41.6 \%$, respectively [22].

In RIDE, 382 patients were randomized (sham $\mathrm{n}=130,0.3 \mathrm{mg} \mathrm{n}=125,0.5 \mathrm{mg}$ $\mathrm{n}=127$ ). At 24 months, ranibizumab-treated patients gained $\geq 3$ lines: $12.3 \%$ of sham patients versus $33.6 \%$ of $0.3-\mathrm{mg}$ and $45.7 \%$ of $0.5-\mathrm{mg}$ ranibizumab (both $\mathrm{p}<0.0001$ ) [15].

Visual acuity (VA) outcomes in ranibizumab group were consistent at month 24 through month 36. Proportions of patients who gained $\geq 3$ lines from baseline at month 36 in the sham $/ 0.5 \mathrm{mg}$, $0.3 \mathrm{mg}$, and $0.5 \mathrm{mg}$ ranibizumab groups were $19.2 \%, 36.8 \%$, and $40.2 \%$, respectively [22].

A "head to head" study, multicenter trial comparing ranibizumab, repackage bevacizumab, and 


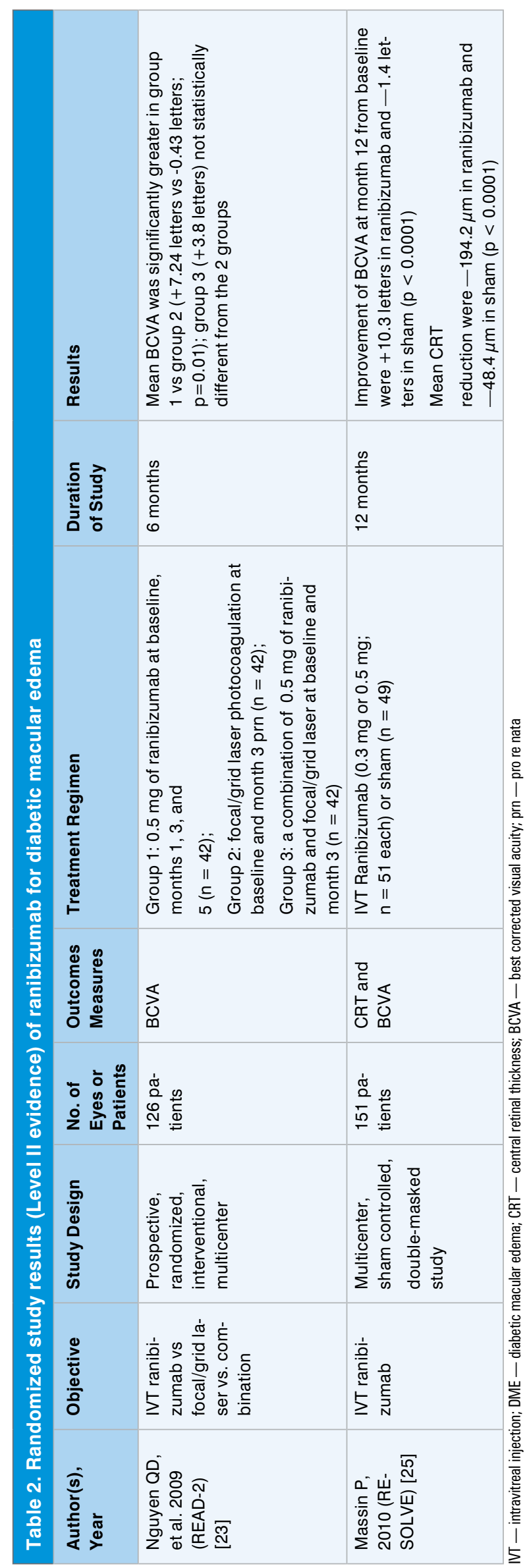

aflibercept in United States. Six hundred and sixty adults with DME was randomized to receive intravitreal injection $2.0 \mathrm{mg}$ aflibercept $(\mathrm{n}=224)$, $1.25 \mathrm{mg}$ bevacizumab $(\mathrm{n}=218)$, or 0.3 ranibizumab $(\mathrm{n}=218)$ every 4 weeks based on criteria in the protocol. If DME persisted after 6 months, focal/grid laser photocoagulation could be added $[16,17]$.

Improvement in mean VA from baseline to 1 year were 13.3 letters with aflibercept, 9.7 letters with bevacizumab, and 11.2 letters with ranibizumab. The difference in the improvement between 3 anti-VEGF was not clinically meaningful because it was driven by the eyes with worse visual acuity at baseline ( $\mathrm{p}<0.001$ for interaction) [16].

When the baseline of visual acuity was 78 to 69 letters (equivalent to approximately 20/32 to 20/40) (51\% participants), the mean improvement was 8.0 letters with aflibercept, 7.5 letters with bevacizumab, and 8.3 letters with ranibizumab ( $p>0.50$ for each pairwise comparison).

There were no significant differences among the study groups in the rates of serious adverse events [16].

In 2-year, median number of injection for aflibercept, bevacizumab, and ranibizumab were 5 , 6 , and 6 , respectively. While the median number over 2 years were 15,16, and 15 in the aflibercept, bevacizumab, and ranibizumab groups, respectively. Forty one percent in aflibercept groups, $64 \%$ in bevacizumab group, and $52 \%$ in ranibizumab groups was administered focal/grid laser photocoagulation (aflibercept vs either ranibizumab or bevacizumab and bevacizumab vs ranibizumab all $\mathrm{p}<0.05$ ) [17].

Mean VA improvement at 2 years were 12.8, 10.0 , and 12.3 letters in aflibercept, bevacizumab, and ranibizumab respectively. The study concluded not only aflibercept, bevacizumab, and ranibizumab showed VA improvement from baseline to 2 years but also a decreased number of injections in year 2. Aflibercept had superior VA outcome compared with bevacizumab in 2-year but the superiority compared with ranibizumab that is shown in year 1 is no longer shown in year 2 [17].

The regimen used in the "head to head" trials is not reflected the clinical practice in Indonesia where ranibizumab available and approved by Indonesian health authority is $0.5 \mathrm{mg}$.

RESOLVE and READ-2 studies are 2 level II studies reported ranibizumab monotherapy or combination improved BCVA until 1 to 2 years compared with no treatment or with laser [23-25]. One 
level II study, READ-2, showed the mean decrease of CRT is significant compared sham patients. [25]

READ-2 conducted in multicenter, 126 DME patients randomized into three groups. Group 1 receive 0.5 ranibizumab at baseline, month 1 , month 3 , and month $5(\mathrm{n}=42)$; group 2 received focal/grid laser photocoagulation at baseline and month 3 pro re nata $(\mathrm{n}=42)$, or group 3 is combination of $0.5 \mathrm{mg}$ ranibizumab and focal/grid laser at baseline and month $3(\mathrm{n}=42)[12,13]$.

The primary endpoint month 6 , the mean change of BCVA was significantly greater in group 1 compared with group $2(+7.2$ vs. -0.43 letters, $\mathrm{p}=0.01)$, and group $3(+3.8$ letters) was not statistically different from the other 2 groups. Improvement of $\geq 3$ lines occurred in $22 \%$ group 1, $0 \%$ in group $2(\mathrm{p}=0.002)$, and $8 \%$ in group 3 [24].

After 6 months, most patients were continued with ranibizumab, 33 patients in group 1, $34 \mathrm{pa}-$ tients in group 2, and 34 patients in group 3 remained in the study through 24 months, with mean improvement in BCVA 7.7, 5.1, and 6.8 letters at month 24 . Patients who gained $\geq 3$ lines was $24 \%$, $18 \%$, and $26 \%$ at month 24 [24].

In RESOLVE study, phase II clinical trial, 151 patients was randomized to ranibizumab $0.3 \mathrm{mg}(\mathrm{n}=51)$, ranibizumab $0.5 \mathrm{mg}(\mathrm{n}=51)$, or sham treatment $(\mathrm{n}=49)$ three monthly injection. Thereafter, treatment could be stopped or reinitiated with an opportunity for rescue laser photocoagulation (based on protocol). After month 1, the ranibizumab dosage (or sham) could be doubled to $0.6 \mathrm{mg}$ (for ranibizumab $0.3 \mathrm{mg}$ ) and $1.0 \mathrm{mg}$ (for ranibizumab $0.5 \mathrm{mg}$ ) if met indicated by specific study criteria.

At month 12, BCVA improvement from baseline were +10.3 letters in ranibizumab group and decline in sham group by -1.4 letters $(\mathrm{p}<0.0001)$. Mean CRT reduction is $-194.2 \mu \mathrm{m}$ with ranibizum$\mathrm{ab}$ and $-48.4 \mu \mathrm{m}$ with sham $(\mathrm{p}<0.0001)$. In ranibizumab group, $60.8 \%$ gain $\geq 10$ letters from baseline and $18.4 \%$ in sham group $(\mathrm{p}<0.0001)$ [25].

\section{CONCLUSIONS}

Review from several level I and level II intravitreal ranibizumab injection studies suggests that ranibizumab alone and/or combination with laser is safe and effective for DME patients for over 2 years treatment.

Comparison with other anti-VEGF also suggest that ranibizumab is effective for DME patients for over 2 years treatment. Future research on the safety and effective ranibizumab $0.5 \mathrm{mg}$ compared with other anti-VEGF is required.

\section{ACKNOWLEDGEMENTS}

The authors thanks to the Universitas Padjajaran, Universitas Indonesia, and Universitas Hasanudin Central Library for providing the literature access.

\section{Conflict of interest:}

The authors declare no conflict of interest.

\section{REFERENCES}

1. Cho NH, et al. IDF Diabetes Atlas, International Diabetes Federation (IDF), Brussels, Belgium, 7th edition. 2015.

2. American Diabetes Association. Diagnosis and Classification of Diabetes Mellitus. Diabetes Care. 2014; 37(suppl1): 81-90.

3. Cheung N, et al. et al.. Diabetic Retinopathy Lancet. 2010; 376: 124-36.

4. Diabetic Retinopathy Preferred Practice Pattern ${ }^{\circledR}$ ("PPP") guidelines. Updated 2016. https://www.aao.org/preferred-practice-pattern/ diabetic-retinopathy-ppp-updated-2016. (Accessed on 14th Aug).

5. Yau JWY, Rogers SL, Kawasaki R, et al. Meta-Analysis for Eye Disease (META-EYE) Study Group. Global prevalence and major risk factors of diabetic retinopathy. Diabetes Care. 2012; 35(3): 556-564, doi: 10.2337/dc11-1909, indexed in Pubmed: 22301125.

6. Lang GE. Diabetic macular edema. Ophthalmologica. 2012; 227 Suppl 1: 21-29, doi: 10.1159/000337156, indexed in Pubmed: 22517122.

7. Scholl S, Augustin A, Loewenstein A, et al. Pathophysiology of macular edema. Ophthalmologica. 2010; 224 Suppl 1: 8-15, doi: 10.1159/000315155, indexed in Pubmed: 20714176.

8. Nguyen QD, Tatlipinar S, Shah SM, et al. Vascular endothelial growth factor is a critical stimulus for diabetic macular edema. Am J Ophthalmol. 2006; 142(6): 961-969, doi: 10.1016/j.ajo.2006.06.068, indexed in Pubmed: 17046701.

9. https://www.elsevier.com/_data/promis_misc/623124los.pdf. (Accessed on 28 Aug 2017).

10. Ferrara N, Damico L, Shams N, et al. Development of ranibizumab, an anti-vascular endothelial growth factor antigen binding fragment, as therapy for neovascular age-related macular degeneration. Retina. 2006; 26(8): 859-870, doi: 10.1097/01 iae.0000242842.14624.e7, indexed in Pubmed: 17031284

11. Chun DW, Heier JS, Topping TM, et al. A pilot study of multiple intravitreal injections of ranibizumab in patients with center-involving clinically significant diabetic macular edema. Ophthalmology. 2006; 113(10): 1706-1712, doi: 10.1016/j.ophtha.2006.04.033, indexed in Pubmed: 17011952.

12. EDWARDS P. Randomized trial evaluating ranibizumab plus prompt or deferred laser or triamcinolone plus prompt laser for diabetic macular edema. Acta Ophthalmologica. 2010; 88: 0-0, doi: 10.1111/j.17553768.2010.4111.x.

13. Elman MJ, Bressler NM, Qin $\mathrm{H}$, et al. Diabetic Retinopathy Clinical Research Network. Expanded 2-year follow-up of ranibizumab plus prompt or deferred laser or triamcinolone plus prompt laser for diabetic macular edema. Ophthalmology. 2011; 118(4): 609-614, doi: 10.1016/j.ophtha.2010.12.033, indexed in Pubmed: 21459214.

14. Sivaprasad S, Regnier SA, Fajnkuchen F, et al. RESTORE study group. The RESTORE study: ranibizumab monotherapy or combined with laser versus laser monotherapy for diabetic macular edema. Ophthalmology. 2011; 118(4): 615-625, doi: 10.1016/j.ophtha.2011.01.031, indexed in Pubmed: 21459215.

15. Nguyen QD, Brown DM, Marcus DM, et al. RISE and RIDE Research Group. Ranibizumab for diabetic macular edema: results from 2 phase III randomized trials: RISE and RIDE. Ophthalmology. 2012; 119(4): 789-801, doi: 10.1016/j.ophtha.2011.12.039, indexed in Pubmed: 22330964.

16. Wells JA, Glassman AR, Ayala AR, et al. Diabetic Retinopathy Clinical Research Network. Aflibercept, bevacizumab, or ranibi- 
zumab for diabetic macular edema. N Engl J Med. 2015; 372(13): 1193-1203, doi: 10.1056/NEJMoa1414264, indexed in Pubmed: 25692915 .

17. Wells J, Glassman A, Ayala A, et al. Aflibercept, Bevacizumab, or Ranibizumab for Diabetic Macular Edema. Ophthalmology. 2016; 123(6): 1351-1359, doi: 10.1016/j.ophtha.2016.02.022.

18. Elman MJ, Qin H, Aiello LP, et al. Diabetic Retinopathy Clinical Research Network. Intravitreal ranibizumab for diabetic macular edema with prompt versus deferred laser treatment: three-year randomized trial results. Ophthalmology. 2012; 119(11): 2312-2318, doi: 10.1016/j. ophtha.2012.08.022, indexed in Pubmed: 22999634.

19. Elman MJ, Ayala A, Bressler NM, et al. Diabetic Retinopathy Clinical Research Network. Intravitreal Ranibizumab for diabetic macular edema with prompt versus deferred laser treatment: 5 -year randomized trial results. Ophthalmology. 2015; 122(2): 375-381, doi: 10.1016/j. ophtha.2014.08.047, indexed in Pubmed: 25439614.

20. Lang GE, Berta A, Eldem BM, et al. RESTORE Extension Study Group. Two-year safety and efficacy of ranibizumab $0.5 \mathrm{mg}$ in diabetic macular edema: interim analysis of the RESTORE extension study. Ophthalmology. 2013; 120(10): 2004-2012, doi: 10.1016/j.ophtha.2013.02.019, indexed in Pubmed: 23725735.
21. Schmidt-Erfurth U, Lang GE, Holz FG, et al. RESTORE Extension Study Group. Three-year outcomes of individualized ranibizumab treatment in patients with diabetic macular edema: the RESTORE extension study. Ophthalmology. 2014; 121(5): 1045-1053, doi: 10.1016/j. ophtha.2013.11.041, indexed in Pubmed: 24491642.

22. Brown D, Nguyen $Q$, Marcus D, et al. Long-term Outcomes of Ranibizumab Therapy for Diabetic Macular Edema: The 36-Month Results from Two Phase III Trials. Ophthalmology. 2013; 120(10): 2013-2022, doi: 10.1016/j.ophtha.2013.02.034.

23. Massin P, et al. Safety and Efficacy of Ranibizumab in Diabetic Macular Edema (RESOLVE Study). Diabetes Care. 2010; 33: 2399-2405.

24. Nguyen QD, Shah SM, Heier JS, et al. READ-2 Study Group. Primary End Point (Six Months) Results of the Ranibizumab for Edema of the mAcula in diabetes (READ-2) study. Ophthalmology. 2009; 116(11): 2175-21781.e1, doi: 10.1016/j.ophtha.2009.04.023, indexed in Pubmed: 19700194.

25. Nguyen OD, Shah SM, Khwaja AA, et al. READ-2 Study Group. Two-year outcomes of the ranibizumab for edema of the $\mathrm{mAc}$ ula in diabetes (READ-2) study. Ophthalmology. 2010; 117(11): 2146-2151, doi: 10.1016/j.ophtha.2010.08.016, indexed in Pubmed: 20855114. 